\title{
SPECTRAL ESTIMATES FOR DIRICHLET LAPLACIAN ON TUBES WITH EXPLODING TWISTING VELOCITY
}

\author{
DIANA BARSEGHYAN AND ANDRII KHRABUSTOVSKYI
}

\begin{abstract}
We study the spectrum of the Dirichlet Laplacian on an unbounded twisted tube with twisting velocity exploding to infinity. If the tube cross section does not intersect the axis of rotation, then its spectrum is purely discrete under some additional conditions on the twisting velocity (D. Krejčiřík, 2015). In the current work we prove a Berezin type upper bound for the eigenvalue moments.
\end{abstract}

Mathematics subject classification (2010): 35P20, 35P15, 81Q10, 81Q37.

Keywords and phrases: Dirichlet Laplacian, twisted tube, discrete spectrum, eigenvalue bounds.

\section{REFERENCES}

[1] F. A. BEREZIN, Covariant and contravariant symbols of operators, Mathematics of the USSR. Izvestiya 6 (1973), 1117-1151, translation from Izv. Ross. Akad. Nauk Ser. Mat. 6, 1134-1167 (1972).

[2] Ph. BRIET, H. HAMmedi, D. KREJČIŘÍK, Hardy inequalities in globally twisted waveguides, Letters in Mathematical Physics 105, 7 (2015), 939-958.

[3] Ph. Briet, H. KovařIK, G. RAIKov, E. SOCCORZI, Eigenvalue asymptotics in a twisted waveguide, Communications in Partial Differential Equations 34, 8 (2009), 818-836.

[4] G. Bouchitté, M. L. Mascarenhas, L. Trabucho, On the curvature and torsion effects in one-dimensional waveguides, ESAIM: Control, Optimization and Calculus of Variations 13, 4 (2007), 793-808.

[5] B. Chenaud, P. Duclos, P. Freitas, D. KRejčIŘíí, Geometrically induced discrete spectrum in curved tubes, Differential Geometry and its Applications 23, 2 (2005), 95-105.

[6] P. Duclos, P. Exner, Curvature-induced bound states in quantum waveguides in two and three dimensions, Reviews in Mathematical Physics 7, 1 (1995), 73-102.

[7] D. E. Edmunds, W. D. Evans, Spectral theory and differential operators, Oxford University Press, Oxford, 1987.

[8] T. EKholm, H. KovaŘíK, D. KRejČIŘí́, A Hardy inequality in twisted waveguides, Archive for Rational Mechanics and Analysis 188, 2 (2008), 245-264.

[9] P. EXner, D. BARSEghyan, Spectral estimates for Dirichlet Laplacians on perturbed twisted tubes, Operators and Matrices 8, 1 (2014), 167-183.

[10] P. EXNer, H. Kovař́í, Spectrum of the Schrödinger operator in a perturbed periodically twisted tube, Letters in Mathematical Physics 73, 3 (2005), 182-192.

[11] P. EXner, H. KovaŘík, Quantum Waveguides, Springer, Heidelberg, 2015.

[12] P. EXNER, P. SEBA, Bound states in curved quantum waveguides, Journal of Mathematical Physics 30, 11 (1989), 2574-2580.

[13] J. Goldstone, R. L. JafFe, Bound states in twisting tubes, Physical Review B 45, 24 (1992), 14100-14107.

[14] V. V. GRUSHIN, On the eigenvalues of a finitely perturbed Laplace operator in infinite cylindrical domains, Mathematical Notes 75, 3-4 (2004), 331-340; translation from Mat. Zametki 75, no. 3, 360-371 (2004).

[15] V. V. GRUSHIN, Asymptotic behavior of the eigenvalues of the Schrödinger operator with transverse potential in weakly curved infinite cylinders, Mathematical Notes 77, 4 (2005), 606-613; translation from Mat. Zametki 77, no. 5, 656-664 (2005). 
[16] D. KREJČIŘíK, Waveguides with asymptotically diverging twisting, Applied Mathematics Letters 46 (2015), 7-10.

[17] D. KREJČIŘ́íK, Twisting versus bending in quantum waveguides, Analysis on Graphs and Applications (Cambridge 2007), Proceedings of Symposia in Pure Mathematics 77, American Mathematical Society, Providence, RI, 2008, 617-636.

[18] D. KREJČIŘík, E. ZuAZUA, The Hardy inequality and the heat equation in twisted tubes, Journal de Mathématiques Pures et Appliquées 4, 3 (2010), 277-303.

[19] A. LapteV, T. WeIDL, Sharp Lieb-Thirring inequalities in high dimensions, Acta Mathematica 184, $1(2000), 87-100$.

[20] E. H. Lieb, W. ThiRRING, Inequalities for the moments of the eigenvalues of the Schrödinger Hamiltonian and their relation to Sobolev inequalities, in Studies in Mathematical Physics, Essays in Honor of Valentine Bargmann (E. Lieb, B. Simon and A. S. Wightman, eds.); Princeton Univ. Press, Princeton, 1976; pp. 269-330.

[21] W. RENGER, W. Bulla, Existence of bound states in quantum waveguides under weak conditions, Letters in Mathematical Physics 35, (1995), 1-12.

[22] G. Rozenblum, Distribution of the discrete spectrum of singular differential operators, Soviet Mathematics. Doklady 13 (1972) (1972), 245-249; translation from Dokl. Akad. Nauk SSSR 202, 10121015 (1972). 